OPEN ACCESS

Edited by:

Gian Mauro Manzoni,

University of eCampus, Italy

Reviewed by:

Bárbara Nazaré,

Universidade Católica Portuguesa,

Portugal

Zezhi Li,

Shanghai Jiao Tong University, China

Eleftherios Spartalis,

National and Kapodistrian University

of Athens, Greece

${ }^{*}$ Correspondence:

Miguel Landa-Blanco

miguel.landa@unah.edu.hn

Specialty section:

This article was submitted to

Health Psychology,

a section of the journal

Frontiers in Psychology

Received: 07 April 2020

Accepted: 29 March 2021

Published: 22 April 2021

Citation:

Landa-Blanco M

Landa-Blanco A, Mejia-Suazo CJ and Martínez-Martínez CA (2021)

Coronavirus Awareness and Mental Health: Clinical Symptoms and Attitudes Toward Seeking

Professional Psychological Help.

Front. Psychol. 12:549644.

doi: 10.3389/fpsyg.2021.549644

\section{Coronavirus Awareness and Mental Health: Clinical Symptoms and Attitudes Toward Seeking Professional Psychological Help}

\author{
Miguel Landa-Blanco ${ }^{1 *}$, Ana Landa-Blanco ${ }^{2}$, Claudio J. Mejía-Suazo ${ }^{3}$ and \\ Carlos A. Martínez-Martínez ${ }^{4}$
}

${ }^{1}$ Clinical Psychology, Faculty of Social Sciences, School of Psychological Sciences, National Autonomous University of Honduras, Tegucigalpa, Honduras, ${ }^{2}$ Social and Economic Research, Faculty of Economy and Management, National Autonomous University of Honduras, Tegucigalpa, Honduras, ${ }^{3}$ Faculty of Sciences, School of Biology, National Autonomous University of Honduras, Tegucigalpa, Honduras, ${ }^{4}$ Faculty of Medical Sciences, National Autonomous University of Honduras, Tegucigalpa, Honduras

The current study analyzed the relationship between Coronavirus (COVID-19) Awareness, mental health, and willingness to seek professional psychological help. This was made through a quantitative approach, using online questionnaires to collect data from 855 subjects. The questionnaires included the Brief Symptom Inventory (BSI53) to measure mental health indicators, the Attitudes Toward Seeking Professional Psychological Help Scale-Short Form, and the Coronavirus Awareness Scale-10 (CAS-10). An Exploratory Factor Analysis suggests that three factors underlie the CAS-10: Coronavirus Concern, Exaggerated Perception, and Immunity Perception. Results indicate a significant positive correlation between Coronavirus Concern and both general anxiety and phobic anxiety symptoms. Immunity Perception is positively related to paranoid ideation and psychotic symptoms. A Mediation Analysis determined that Coronavirus Concern has a significant positive direct effect on Openness to Seeking Psychological Treatment (OSPT), while Exaggerated Perception and Immunity Perception scores have significant direct negative effects on the Value and Need in Seeking Treatment (VNST) scores. Indirectly, the relationship between Coronavirus Concern and OPST is significantly mediated by anxiety symptoms. Similar results were found for the VNST subscale. There is a negative significant effect of Immunity Perception over OSPT mediated by Paranoid Ideation. However, the overall model only achieved small $r^{2}$ coefficients for the OSPT (0.060) and VNST (0.095) scores. Comparisons in Coronavirus Awareness between sex, age, and the presence of children and older adults at home were also made. These results are discussed regarding their practical implications for mental health providers and policymakers.

\footnotetext{
Keywords: pandemics, mental health, psychological help, health psychology, public health
} 


\section{INTRODUCTION}

\section{Origins of COVID-19}

Coronavirus is one of the most important pathogens that causes respiratory infections in humans. On December 2019, an outbreak of pneumonia of unknown cause was reported in the city of Wuhan, China. By January 2020, the pathogen was isolated from these patients and was identified as a novel Coronavirus (Severe Acute Respiratory Syndrome-Coronavirus 2). It was highly suspected that the outbreak started in a Huanan seafood market, a place where live animals such as bats, birds, snakes and frogs were sold (Shereen et al., 2020). This disease is highly contagious, initially from zoonotic transmission, and later from human to human, by coughing, sneezing or having close contact with an infected person's respiratory droplets (Rothan and Byrareddy, 2020; Shereen et al., 2020).

The most common symptoms of COVID-19 illness are fever, cough, dyspnea, and myalgia. Populations at higher risk include older adults and people with underlying conditions like diabetes, hypertension, or coronary heart disease (Mesa Vieira et al., 2020). In such cases, health complications can quickly progress to Acute Respiratory Distress Syndrome (ARDS) or end-organ failure (Wu et al., 2020).

On the other hand, the evidence shows that only a small number of children that are COVID-19 positive develop a severe health condition. However, asymptomatic children could be playing a relevant part in the spread of the virus (Dervrim and Bayram, 2020). It's important to reduce the increasing cases to avoid a higher fatality rate, especially for healthcare systems that are not prepared for this kind of pandemic, like in the Latin American region (Rodríguez-Morales et al., 2020).

\section{Prevalence of COVID-19}

The World Health Organization (2020a) at the beginning of 2020 considered the outbreak of COVID-19 an international public health emergency. The virus kept spreading quickly in a great number of territories around the world, by March of 2020 it was cataloged as a pandemic. By May 27th, 2020, this number increased considerably, registering 5,491,678 confirmed cases and 349,190 deaths worldwide, with a great prevalence of cases in the American region (World Health Organization, 2020b). The spreading of Coronavirus in Latin American countries has presented an aggressive dynamic that suggests a difficult scenario for low-income nations (Caicedo-Ochoa et al., 2020). In the case of Honduras, by the date data for this research was collected (16th-23rd of March), the virus was just beginning to spread, with 30 confirmed cases and 0 deaths. By May 27th, 2020, these numbers increased alarmingly, reaching 4,401 confirmed cases and 188 fatalities (Honduras Health Secretary, 2020).

\section{Mental Health in the Context of COVID-19}

According to the World Health Organization (2003), mental health is an important part of the human condition, along with the physical and social domains. Mental health concepts are related to subjective well-being, autonomy, the capability of identifying one's potential, the ability to manage stress, work in a productive way and be capable of contributing to their social environment. Mental health is associated with a balance between the person and the environment. This is influenced by a series of biological, psychological, social, and cultural factors (Korkeila et al., 2003). Recent outbreaks such as SARS, Zika, MERS, and Ebola have shown that a health crisis is a stressful situation. These concerns may be related to the risk of acquiring the virus or passing it on to others, the presence of symptoms of other health conditions that could be confused with COVID19 , and physical and mental health deterioration in vulnerable populations. Other concerns are related to the uncertainty of the long-term consequences in the health, social and economic domains (Huremovié, 2019; Inter-Agency Standing Committee, 2020; Wang et al., 2020).

The constant fear of becoming infected or dying, as well as seeing other people die, are just one of the effects caused by outbreaks of epidemics and pandemics on mental health. People who become infected may be attacked and marginalized because they are perceived as "contaminated" (Huremovié, 2019; Wang et al., 2020). Likewise, there is a direct correlation between the growing crisis and the negative impact on the economy, health and educational systems (Sim et al., 2010; Van Bortel et al., 2016). This vulnerability can also be related to mental health issues to specific populations like older adults (El Hayek et al., 2020).

One of the most relevant public health measures to reduce the number of people infected with COVID-19 has been social distancing and quarantine (Wilder-Smith et al., 2020). Quarantine has shown to have negative psychological effects on people with and without pre-existing mental health problems. People under quarantine may experience symptoms related to anxiety, depression, and post-traumatic stress symptoms (Brooks et al., 2020). In addition, media can influence the public by doing "agenda-setting," which occurs when a problem receives massive coverage, making it more important to the public (Rubin et al., 2010; Rubin and Wessly, 2020). People's lack of knowledge about a disease leads to misinformation and the spread of rumors, which could lead to harmful effects on mental health (Fernández Poncela, 2012).

Although there are many instruments designed to screen psychological symptoms, the Brief Symptom Inventory-53 (BSI-53) has been widely used in different contexts. The BSI-53 measures symptoms related to Anxiety, Depression, Phobic Anxiety, Hostility, Interpersonal Sensitivity, ObsessiveCompulsive traits, Paranoid Ideation, Psychoticism, and Somatization (Derogatis, 1993). The following description provides a brief overview of these symptoms during the pandemic and confinement period:

- Anxiety: the contextual presence of different diseases or viruses can cause anxiety in the general population. Specific outbreaks (like Zika, Ebola, etc.) may detonate diverse patterns of health anxiety responses (Blakey and Abramowitz, 2017). Recent research made within the COVID-19 outbreak suggests a high prevalence of anxiety symptoms among the population (Rajkumar, 2020). 
- Depression: has been described as one of the most prevalent symptoms among the general population during the current COVID-19 pandemic (Rajkumar, 2020).

- Phobic anxiety: recent studies have concluded that the fear of COVID-19 is related to variables such as perceived infectability and germ aversion (Kwasi Ahorsu et al., 2020).

- Hostility: during the SARS outbreak of 2003, health-care workers who were in quarantine reported high levels of anger, frustration, and annoyance (Brooks et al., 2020).

- Interpersonal sensitivity: is defined as a disproportionate awareness of other people's conducts and emotions (Mushtaq et al., 2017). Limited research is available on the topic of interpersonal sensitivity in the context of COVID-19. However, there is evidence that suggests that such construct is an important factor when promoting social functioning in help-seeking individuals (Masillo et al., 2015).

- Obsessive-Compulsive symptoms: the COVID-19 outbreak may trigger such symptoms. This can be exacerbated by the biosecurity measures taken to prevent COVID-19, such as hand washing (quality and frequency), interaction with others with suspected exposure, excessive mediatic information, etcetera (Debanjan, 2020).

Paranoid Ideation: recent research suggests that subjects with a history of paranoid ideation may report high levels of fear related to COVID-19 transmission (Vinkers et al., 2020). A study in Indian population reported that a significant percentage of respondents showed health-related paranoia regarding COVID19 (Roy et al., 2020).

- Psychoticism: a recent study concluded that some subjects who tested positive on COVID-19 presented stresstriggered psychotic symptoms. However, further research is yet needed on the subject to explore alternatives explications to this reaction (Ferrando et al., 2020).

- Somatization: is characterized by the presence of physical symptoms related to dysfunctional concerns. Recent evidence suggests that the current fear of COVID-19 infection may aggravate pre-existing conditions related to somatic symptom disorders (Colizzi et al., 2020).

However, the Latino population have a tendency to underestimate the relevance of mental health care (Liu et al., 2020; Torres et al., 2020). Latin American population tends to avoid seeking psychological help for fear of the diagnosis they may receive and its associated social stigma (Mascayano et al., 2015). Added to the above, are the religious and cultural beliefs in Latin America which could play an important role in the decision of not seeking psychological help (Caplan, 2019). Despite this cultural resistance, the School of Psychological Science of the National Autonomous University of Honduras, launched an online chat service to provide psychological help amidst the COVID-19 crisis. As of June 11, 2020, more than 711 persons had been attended through the application (School of Psychological Sciences, 2020). This data evidences the demand for mental health services among the Honduran population.

\section{COVID-19 Awareness}

The present study takes into consideration Coronavirus Awareness in relation to mental health and attitudes toward seeking professional psychological help. Coronavirus Awareness is defined as the degree in which people are conscious of the meaning, implications, prevention strategies, and seriousness of the spreading of COVID-19. Recently, a study used Google Trends to analyze the search volume of queries regarding COVID-19 and related terms. The results indicate that people respond temporarily to local propaganda regarding the virus (indicating awareness), however, this attention spam had a short duration (Hu et al., 2020).

Research suggests that demographic variables, such as sex, may be related to Coronavirus Awareness. A study made within the United States of America (USA) context compared the proportion of female and male respondents who reported to be concerned about the COVID-19 situation. Results indicate that when compared to men, there is a higher proportion of women that claim to be concerned about their risk of exposure to COVID-19. Women are also more concerned about contagion risk in their families, loss of economic income and access to COVID-19 testing and treatment (Frederiksen et al., 2020).

Household configuration may also be related to Coronavirus Awareness. Men and women with children are more likely to report COVID-19 related concerns (risk of exposure and loss of economic income), when compared with people who do not have children (Frederiksen et al., 2020). In addition, older adults have a high COVID-19 physical vulnerability (Mesa Vieira et al., 2020) and are also exposed to the social, psychological and economic repercussions of the pandemic. Furthermore, quarantine measures have also promoted intergenerational cohesion, improving the bond older adults have with their own family members as well as with non-related younger people (Morrow-Howell et al., 2020). Age is another variable to consider when analyzing COVID-19 Awareness. Previous research in the United States concluded that the proportion of older adults (>60 years) reporting health-related concerns about the COVID19 situation was higher than in younger adults ( $<60$ years) (Hamel et al., 2020). However, no data is yet available for the Central American context.

\section{Purpose of the Study}

Reflecting on what has been previously stated, the current study assumes the following premises: (a) the COVID-19 situation is considered a stressor (Wang et al., 2020), (b) stress is strongly related to the presence of mental health disorders (Wu et al., 2020), (c) subjective needs play an important role in help-seeking behaviors (Nagai, 2015); therefore, we propose to analyze a causal model based on these assumptions contextualized within the COVID-19 crisis (see Figure 1).

Consequently, the purpose of this study was to analyze the relationship between Coronavirus (COVID-19) Awareness with mental health indicators and the attitude toward seeking professional psychological help. Additional information regarding Coronavirus Awareness and demographic variables were also analyzed, such variables included: age, sex, presence 
of children and older adults at home. To our knowledge, there are no studies in Honduras or the Central American region that evaluate the impact of the COVID-19 situation in mental health.

\section{MATERIALS AND METHODS}

\section{Participants \\ Sampling Method}

A total of 855 participants from Honduras answered an online survey that was spread through social media and by snowball sampling. This online method was selected given the country's quarantine regulations. Each survey was accompanied by an online informed consent which stated the purpose of the study, a confidentiality clause and the main researcher's contact information. The selection criteria for the participants included: (a) being 18 years or older, (b) currently residing in Honduras and, (c) agreeing with the informed consent statement; any violation of these criteria was considered a motive for exclusion.

\section{Characteristics of the Participants}

Of all the respondents, 307 (35.9\%) were male and 548 (64.1\%) female. The average age for male participants was of 27.619 years $(S D=10.284)$, while female mean age was $28.755(S D=10.878)$, however, this difference is not statistically significant, $t(853)=-$ 1.494, $p=0.135$. On the other hand, $645(75.4 \%)$ respondents were single, while the remaining $210(24.6 \%)$ were married. Regarding household configuration, 444 (51.9\%) respondents reported to live at home with children under 12 years old, while $327(38.2 \%)$ lived at home with people 60 years or older.

\section{Measures}

\section{Brief Symptom Inventory-53}

The Brief Symptom Inventory-53 (BSI-53) is a self-reported questionnaire designed to screen the presence of clinical symptoms, specifically Depression $(\alpha=0.892)$, Anxiety $(\alpha=0.849)$, Phobic Anxiety ( $\alpha=0.795)$, Somatization $(\alpha=0.876)$, Interpersonal Sensitivity $(\alpha=0.836)$, Obsessive-Compulsive traits $(\alpha=0.900)$, Hostility $(\alpha=0.851)$, Paranoid Ideation ( $\alpha=0.799)$, and Psychoticism $(\alpha=0.804)$. The BSI-53, consist on 53 items, each of them scored in a 5-point Likert scale format (Derogatis, 1993), scores closer to 0 indicate a lower symptomatic prevalence, while scores near 4 indicate a higher prevalence. Other authors report good reliability scores for the BSI-53, with an overall Cronbach's alpha of 0.972 (Mohammad et al., 2019). Previous studies have concluded that the BSI- 53 is an objective and precise tool to evaluate the presence of psychopathological symptoms (Ruckenstein and Staab, 2001).

\section{Attitudes Toward Seeking Professional Psychological Help Scale-Short Form \\ The Attitudes Toward Seeking Professional Psychological Help Scale-Short Form (ATSPPH-SF) consists of 10 items with Likert- type responses (Fischer and Farina, 1995). Scores closer to 1 indicate a negative attitude, while scores near 4 indicate a favorable attitude toward seeking professional psychological help}

( 1 = disagree, 2 = somewhat disagree, $3=$ somewhat agree, $4=$ agree). The scale has also been validated for a Latino adult population, in which an Exploratory Factor Analysis (EFA) suggested the presence of two different dimensions: Openness to Seeking Treatment ( $\alpha=0.640$; average inter-item $r=0.396$ ) and the Perceived Value and Need in Seeking Treatment (VNST) $(\alpha=0.756$; average inter-item $r=0.526)$. The overall scale had a Cronbach's alpha of 0.758 and an average inter-item $r$ of 0.461. A Confirmatory Factor Analysis (CFA) based upon the data of the current research validates the two-dimensional nature of the scale proposed by Torres et al. (2020), CFI $=0.972$, TLI $=0.963$, RMSEA $=0.040$.

\section{Coronavirus (COVID-19) Awareness Scale}

The Coronavirus Awareness Scale-10 (CAS-10) is a 10-item questionnaire built by the authors of the current study, each author individually proposed items, which were later discussed by the research team, the more pertinent and well-structured items were selected to be applied in the selected sample. The CAS-10 has a Likert type response set of 5 points (0-4). An EFA analysis with a maximum likelihood extraction method and an oblimin rotation was executed to detect the underlying factorial structure of the scale. This oblique rotation method allows factors to correlate with each other (Field, 2009), as is the case for many psychological constructs. The Barlett's Test of Sphericity $\left[\chi^{2}=1,917.893(d f=45), p<0.001\right]$ and the KMO Measure of Sampling Adequacy (0.804) have an acceptable performance (see Table 1). The three resulting factors are Coronavirus Concern (refers to the preoccupation about getting infected with COVID19), Exaggerated Perception (the belief that the media and governments are overreacting with the COVID-19 situation) and Immunity Perception (the belief that one is not likely to get infected by COVID-19).

Each factor mean is built by averaging the corresponding items raw scores (without reverse coding). Considering item orientation, a higher Coronavirus Concern score (which only contains positive oriented items) indicates a higher Coronavirus Awareness. While high scores on the Exaggerated Perception and Immunity Perception subscales indicate low Coronavirus Awareness. The CAS-10 has a Cronbach's alpha of 0.762, which is considered acceptable (Coolican, 2004). However, given that this coefficient is affected by the number of items in the scale, average inter-item correlations were also obtained for the overall CAS-10 items (0.436). Specifically, the Coronavirus Concern subscale had the highest Cronbach's alpha score $(\alpha=0.715$; average inter-item $r=0.487)$, followed by the Exaggerated Perception ( $\alpha=0.667$; average inter-item $r=0.436)$ and Immunity Perception subscales $(\alpha=0.550$; average inter-item $r=0.381$ ). Given that these average inter-item correlations are between the 0.15 and 0.50 limits, the subscales are considered to be adequately consistent (BrckaLorenz et al., 2013), despite the low number of items included.

\section{Statistical Analysis}

Data was analyzed using Jamovi 1.1 (The Jamovi Project, 2019). First, demographic variables were described using relative and absolute frequencies as well as mean scores and standard 


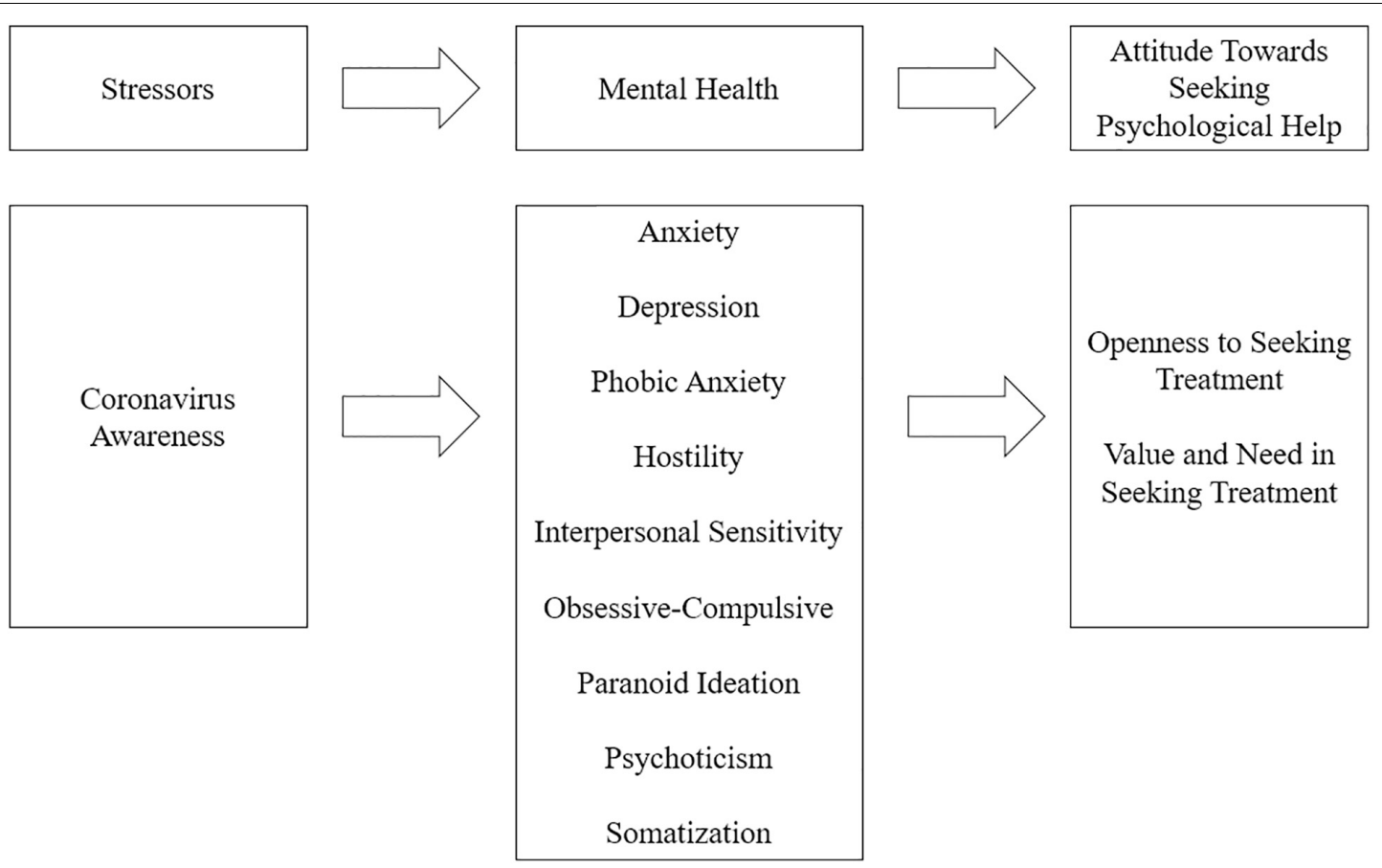

FIGURE 1 | A proposed mediation model with Coronavirus Awareness as predictor, mental health symptoms as mediators and the attitude toward seeking psychological help as outcome.

TABLE 1 | Factor loadings for the CAS-10.

\begin{tabular}{|c|c|c|c|c|}
\hline \multirow[b]{2}{*}{ Item } & \multicolumn{3}{|c|}{ Factor } & \multirow[b]{2}{*}{ Uniqueness } \\
\hline & $\begin{array}{l}\text { Coronavirus } \\
\text { concern }\end{array}$ & $\begin{array}{l}\text { Exaggerated } \\
\text { perception }\end{array}$ & $\begin{array}{l}\text { Immunity } \\
\text { perception }\end{array}$ & \\
\hline $\begin{array}{l}\text { C4. I am concerned about the spread of Coronavirus } \\
\text { (COVID-19). }\end{array}$ & 0.844 & 0.016 & -0.008 & 0.293 \\
\hline C2. I am afraid of catching Coronavirus (COVID-19). & 0.653 & 0.063 & -0.101 & 0.549 \\
\hline C10. Coronavirus (COVID-19) is a serious problem. & 0.539 & -0.210 & 0.090 & 0.611 \\
\hline $\begin{array}{l}\text { C1. I am constantly informed about the situation of the } \\
\text { Coronavirus (COVID-19). }\end{array}$ & 0.431 & -0.009 & 0.031 & 0.821 \\
\hline $\begin{array}{l}\text { C6. I have taken precautions to avoid getting the } \\
\text { Coronavirus (COVID-19). }\end{array}$ & 0.406 & -0.081 & 0.063 & 0.821 \\
\hline $\begin{array}{l}\text { C9. I feel like this Coronavirus issue (COVID-19) is more } \\
\text { paranoia than anything else. }\end{array}$ & -.007 & 0.861 & -0.003 & 0.256 \\
\hline $\begin{array}{l}\text { C8. I believe that quarantine measures to prevent the } \\
\text { spread of Coronavirus (COVID-19) are exaggerated. }\end{array}$ & -0.058 & 0.533 & 0.106 & 0.620 \\
\hline $\begin{array}{l}\text { C3. The media exaggerates about the danger of } \\
\text { contagion of the Coronavirus (COVID-19). }\end{array}$ & 0.039 & 0.492 & 0.020 & 0.765 \\
\hline $\begin{array}{l}\text { C7. I am not worried about getting Coronavirus } \\
\text { (COVID-19). }\end{array}$ & -0.011 & 0.009 & 0.989 & 0.005 \\
\hline C5. I do not think I can get Coronavirus (COVID-19). & 0.068 & 0.248 & 0.301 & 0.811 \\
\hline
\end{tabular}

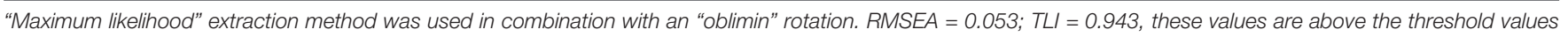

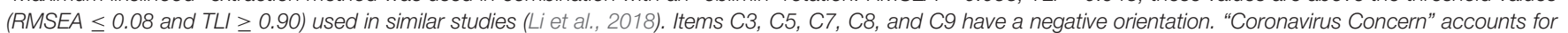

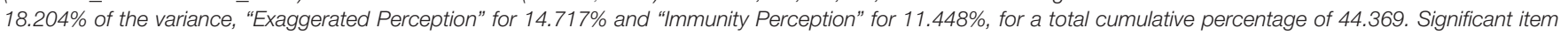
loadings (>0.30) are presented in bold letter.

deviations. Items from the CAS-10 and the ATSPPH-SF with negative orientation were inversely recoded and their structural properties determined with EFA and CFA, respectively. The relationships between CAS-10, BSI-53, and age were determined by Pearson's $r$ coefficient. Between-group comparisons for sex were made through a MANOVA test, while comparisons for household configuration were determined through a Student's $t$-test. 
Finally, a Mediation Analysis was used to study the relationship between Coronavirus Awareness (predictor), BSI-53 symptoms (mediators) and Attitudes Toward Seeking Professional Psychological Help (outcome). This analysis included Delta method standard errors and bias-corrected percentile bootstrap confidence intervals based on 1,000 replications. Such method provides stable and precise coverage rates and has an overall good performance (Biesanz et al., 2010).

\section{Ethical Considerations}

The current research was made in accordance with the Ethical Guidelines provided by the master's degree in Clinical Psychology of the National Autonomous University of Honduras, which approved the present study. An online informed consent was presented to all potential participants, it included information regarding the purpose of the study, an anonymity statement, potential risks and benefits, the name and e-mail of the main researcher. At the end of the survey participants were presented with a web link which redirected to a free online psychological assistance website supported by the National Autonomous University of Honduras.

\section{Coronavirus Awareness and Demographic Variables General Description of Scores}

Most respondents are aware of COVID-19 and its implications. For example, $55.7 \%$ of the respondents totally agreed with the item "I am constantly informed about the Coronavirus situation" and $69.1 \%$ completely agreed that COVID-19 is a serious problem. Nonetheless, a considerable number of participants $(30.4 \%)$ believed that the media makes exaggerated claims about the COVID-19 dangers (see Table 2). The overall CAS-10 mean score was of $3.007(S D=0.651)$, as for the subscales, higher mean scores correspond to Coronavirus Concern $(M=3.356, S D=0.641)$, followed by Exaggerated Perception $(M=1.502, S D=1.072)$ and Immunity Perception $(M=1.105, S D=1.048)$.

\section{Coronavirus Awareness and Sex}

A MANOVA analysis suggests that there is no statistically significant difference $(p<0.05)$ on the Coronavirus Awareness scores compared to the respondent's sex. In this sense, the Coronavirus Concern scores for men $(M=3.320, S D=0.610)$ do not differ significantly when compared to female respondents $(M=3.377, S D=0.657), F(1 ; 673.939)=-1.244, p=0.205$. Male $(M=1.596, S D=1.120)$ and female subjects $(M=1.449$, $S D=1.042)$ report no significant difference in the Exaggerated Perception scores, $F(1 ; 596.423)=1.928, p=0.059$. Similarly, the scores in Immunity Perception do not vary significantly between men $(M=1.085, S D=1.025)$ and women $(M=1.116, S D=1.062)$, $F(1 ; 652.178)=-0.417, p=0.674$.

Coronavirus Awareness and Household Configuration Respondents who dwelled with children (12 years or younger) had significantly $(p<0.05)$ higher scores in the Exaggerated Perception and the Immunity Perception subscales than people

TABLE 2 | Descriptive statistics for each CAS-10 item.

\begin{tabular}{|c|c|c|c|c|c|c|}
\hline CAS-10 items & $\begin{array}{l}\text { Totally disagree } \\
\text { n (\%) }\end{array}$ & $\begin{array}{c}\text { Disagree } \mathrm{n} \\
(\%)\end{array}$ & $\begin{array}{l}\text { Neither agree nor } \\
\text { disagree } \mathrm{n}(\%)\end{array}$ & Agree n (\%) & $\begin{array}{l}\text { Totally agree } n \\
(\%)\end{array}$ & Mean (SD) \\
\hline $\begin{array}{l}\text { C1. I am constantly informed about the } \\
\text { situation of the Coronavirus } \\
\text { (COVID-19). }\end{array}$ & $5(0.60 \%)$ & $23(2.7 \%)$ & 98 (11.5\%) & 253 (29.6\%) & $476(55.7 \%)$ & $3.371(0.834)$ \\
\hline $\begin{array}{l}\text { C2. I am afraid of catching Coronavirus } \\
\text { (COVID-19). }\end{array}$ & $64(7.5 \%)$ & $70(8.2 \%)$ & 133 (15.6\%) & 190 (22.2\%) & 398 (46.5\%) & $2.922(1.272)$ \\
\hline $\begin{array}{l}\text { C3. The media exaggerates about the } \\
\text { danger of contagion of the Coronavirus } \\
\text { (COVID-19). }\end{array}$ & 152 (17.8\%) & 117 (13.7\%) & 173 (20.2\%) & 153 (17.9\%) & 260 (30.4\%) & $2.295(1.469)$ \\
\hline $\begin{array}{l}\text { C4. I am concerned about the spread } \\
\text { of Coronavirus (COVID-19). }\end{array}$ & $15(1.8 \%)$ & $12(1.4 \%)$ & 79 (9.2\%) & 194 (22.7\%) & 555 (64.9\%) & $3.476(0.854)$ \\
\hline $\begin{array}{l}\text { C5. I don't think I can get Coronavirus } \\
\text { (COVID-19). }\end{array}$ & $352(41.2 \%)$ & 185 (21.6\%) & 195 (22.8\%) & 73 (8.5\%) & $50(5.8 \%)$ & $1.163(1.218)$ \\
\hline $\begin{array}{l}\text { C6. I have taken precautions to avoid } \\
\text { getting the Coronavirus (COVID-19). }\end{array}$ & $11(1.3 \%)$ & $19(2.2 \%)$ & $52(6.1 \%)$ & 236 (27.6\%) & 537 (62.8\%) & $3.484(0.812)$ \\
\hline $\begin{array}{l}\text { C7. I'm not worried about getting } \\
\text { Coronavirus (COVID-19). }\end{array}$ & 432 (50.5\%) & 154 (18.0\%) & 139 (16.3\%) & 57 (6.7\%) & 73 (8.5\%) & $1.047(1.305)$ \\
\hline $\begin{array}{l}\text { C8. I believe that quarantine measures } \\
\text { to prevent the spread of Coronavirus } \\
\text { (COVID-19) are exaggerated. }\end{array}$ & 502 (58.7\%) & 147 (17.2\%) & 85 (9.9\%) & $51(6.0 \%)$ & $70(8.2 \%)$ & $0.877(1.284)$ \\
\hline $\begin{array}{l}\text { C9. I feel like this Coronavirus issue } \\
\text { (COVID-19) is more paranoia than } \\
\text { anything else. }\end{array}$ & 351 (41.1\%) & 160 (18.7\%) & $141(16.5 \%)$ & 114 (13.3\%) & 89 (10.4\%) & $1.333(1.392)$ \\
\hline $\begin{array}{l}\text { C10. Coronavirus (COVID-19) is a } \\
\text { serious problem. }\end{array}$ & $12(1.4 \%)$ & $13(1.5 \%)$ & 77 (9.0\%) & 162 (18.9\%) & 591 (69.1\%) & $3.529(0.831)$ \\
\hline
\end{tabular}

The table shows raw scores for negative items (C3, C5, C7, C8, and C9). 
whose households did not have children. No such difference was found in the Coronavirus Concern subscale $(p=0.896)$.

Participants who reported that in their household lived people over the age of 60 had a significantly lower Immunity Perception score than subjects that didn't have older adults at home $(p=0.010)$. No statistically significant difference was found for the Coronavirus Concern subscale $(p=0.162)$ nor the Exaggerated Perception subscale $(p=0.074)$. Table 3 summarizes the descriptive and comparative statistics for the CAS-10 scale regarding household configuration.

\section{Coronavirus Awareness and Age}

Results suggest that there is a significant correlation between the respondent's age and the Coronavirus Awareness subscales. For instance, Coronavirus Concern scores are positively related to the respondent's age $(r=0.116, p<0.001)$; indicating that increases in Coronavirus Concern scores are weakly associated with increases in age and vice versa. There are also weak negative relationships between the Exaggerated Perception and Immunity Perception subscales regarding the respondent's age $(r=-0.171$, $p<0.001 ; r=-0.097, p=0.004$, respectively). It is worth noting that Pearson's $r$ coefficients for all variables are stronger in men than in women (see Table 4).

\section{Coronavirus Awareness and Mental Health \\ Description of BSI-53 Symptoms}

The most intense symptoms reported by the respondents correspond to the Obsessive-Compulsive domain $(M=1.595$, $S D=1.054)$, followed by Anxiety $(M=1.592, S D=0.92)$ and Interpersonal Sensitivity $(M=1.46, S D=1.071)$. The less intense symptoms included: Hostility $(M=1.440, S D=1.021)$, Social Phobia $(M=1.435, S D=1.005)$, Depression $(M=1.378$, $S D=1.035)$, Paranoid Ideation $(M=1.339, S D=0.937)$,

TABLE 3 | Descriptive and comparative statistics for CAS-10 scores according to household configuration.

\begin{tabular}{lccccccc}
\hline Scale & Group & Mean & SD & $\boldsymbol{F}$ & df 1; df 2 & $\boldsymbol{p}$ \\
\hline \multicolumn{2}{l}{$\begin{array}{l}\text { Presence of children at home (<12 years) } \\
\text { Coronavirus concern }\end{array}$} & No & 3.353 & 0.615 & 0.017 & $1 ; 853.00$ & 0.896 \\
& Yes & 3.359 & 0.664 & & & \\
Exaggerated perception & No & 1.422 & 1.094 & 4.410 & $1 ; 840.615$ & 0.036 \\
& Yes & 1.576 & 1.047 & & & \\
Immunity perception & No & 1.021 & 1.026 & 5.121 & $1 ; 851.552$ & 0.024 \\
& Yes & 1.182 & 1.064 & & & \\
Presence of older adults at home $\mathbf{( > 6 0}$ years) & & & \\
Coronavirus concern & No & 3.332 & 0.643 & 1.962 & $1 ; 697.628$ & 0.162 \\
& Yes & 3.395 & 0.635 & & & \\
Exaggerated perception & No & 1.553 & 1.079 & 3.196 & $1 ; 701.942$ & 0.074 \\
& Yes & 1.419 & 1.057 & & & \\
Immunity perception & No & 1.176 & 1.076 & 6.702 & $1 ; 732.372$ & 0.010 \\
& Yes & 0.989 & 0.993 & & & \\
\hline
\end{tabular}

From the total sample size, 444 respondents report the presence of minors ( $<12$ years) at home, while 411 do not. On the other hand, 528 report to live with older adults ( $>60$ years) and 327 do not.
Psychoticism $(M=1.222, S D=0.981)$, and Somatization $(M=1.061, S D=0.897)$. The Overall BSI-53 score was of 1.391 $(S D=0.856)$.

\section{Relationship Between Coronavirus Awareness and BSI-53}

Significant $(p<0.001)$, although weak, relationships were found between the Coronavirus Concern subscale and symptoms of Anxiety, Depression, Phobic Anxiety and Psychoticism. Additionally, Exaggerated Perception relates significantly to symptoms of Anxiety, Depression, Hostility, Interpersonal Sensitivity, Obsessive-Compulsive scores, Paranoid Ideation, Psychoticism, and Somatization. Immunity Perception scores are significantly correlated with Paranoid Ideation and Psychoticism. Nonetheless, it's worth mentioning that all subscale correlation coefficients have a small effect size $(r<0.30)$ (Cohen, 1992). All correlation coefficients between the CAS-10 and the BSI-53 are presented in Table 5.

\section{Coronavirus Awareness and Attitudes Toward Seeking Professional Psychological Help}

Coronavirus Concern scores have a significant $(p=0.003)$ and positive $(\beta=0.178)$ direct effect on Openness to Seeking Psychological Treatment (OSPT). Moreover, the Exaggerated Perception $(\beta=-0.124, p<0.001)$ and Immunity Perception scores $(\beta=-0.104, p=0.003)$ have significant direct negative effects on the VNST scores (see Table 6).

Indirectly, the relationship between Coronavirus Concern and Openness to Seeking Treatment is significantly mediated by Anxiety scores $(\beta=0.060, p=0.006)$. Similar results were found for the VNST subscale $(\beta=0.036, p=0.007)$. On the other hand, there is a negative significant effect of Immunity Perception over Openness to Seeking Treatment mediated by Paranoid Ideation $(\beta=-0.040, p=0.005)$ (see Table 7). Overall, Immunity Perception had a negative and significant total indirect effect on Openness to Seeking Treatment $(\beta=-0.029, p=0.005)$ (see Table 8).

Coronavirus Concern had a significant positive total effect on Openness to Seeking Treatment $(\beta=0.193, p<0.001)$, while both Exaggerated Perception $(\beta=-0.153, p<0.01)$ and Immunity Perception $(\beta=-0.109, p=0.002)$, had significant negative total effects on the VNST scores (see Table 9). However, the overall model only achieved an $r^{2}$ of 0.060 for the OSPT and an $r^{2}$ of 0.095 for the VNST scores.

TABLE 4 | Relationship between CAS-10 subscales and age, compared by the respondent's sex.

\begin{tabular}{lcccc}
\hline Scale & Statistics & General age & Men's age & Women's age \\
\hline Coronavirus concern & $r$ & $0.116^{\star \star \star}$ & $0.152^{\star \star}$ & $0.096^{\star}$ \\
& $p$-value & $<0.001$ & 0.008 & 0.024 \\
Exaggerated perception & $r$ & $-0.171^{* \star *}$ & $-0.225^{\star \star \star}$ & $-0.136^{\star \star}$ \\
& $p$-value & $<0.001$ & $<0.001$ & 0.001 \\
Immunity perception & $r$ & $-0.097^{\star \star}$ & $-0.236^{\star \star \star}$ & -0.028 \\
& $p$-value & 0.004 & $<0.01$ & 0.509
\end{tabular}

Pearson's $r$ coefficient was used to correlate the variables. ${ }^{*} p<0.05,{ }^{* *} p<0.01$, ${ }^{* * *} p<0.001$. 
TABLE 5 | Correlation between CAS-10 and BSI-53 subscales.

\begin{tabular}{|c|c|c|c|c|}
\hline Scale & Statistic & $\begin{array}{c}\text { Coronavirus } \\
\text { concern }\end{array}$ & $\begin{array}{c}\text { Exaggerated } \\
\text { perception }\end{array}$ & $\begin{array}{l}\text { Immunity } \\
\text { perception }\end{array}$ \\
\hline \multirow[t]{2}{*}{ Anxiety } & $r$ & $0.111^{\star \star}$ & $0.074^{\star}$ & -0.033 \\
\hline & $p$-value & 0.001 & 0.030 & 0.332 \\
\hline \multirow[t]{2}{*}{ Depression } & $r$ & $-0.088^{\star \star}$ & $0.165^{\star \star \star}$ & 0.038 \\
\hline & $p$-value & 0.01 & $<0.001$ & 0.269 \\
\hline \multirow[t]{2}{*}{ Phobic anxiety } & $r$ & $0.131^{\star \star \star}$ & 0.021 & -0.06 \\
\hline & $p$-value & $<0.001$ & 0.546 & 0.081 \\
\hline \multirow[t]{2}{*}{ Hostility } & $r$ & -0.030 & $0.162^{\star \star \star}$ & 0.045 \\
\hline & $p$-value & 0.383 & $<0.001$ & 0.186 \\
\hline \multirow{2}{*}{$\begin{array}{l}\text { Interpersonal } \\
\text { sensitivity }\end{array}$} & $r$ & -0.060 & $0.131^{\star \star \star}$ & 0.049 \\
\hline & $p$-value & 0.079 & $<0.001$ & 0.155 \\
\hline \multirow{2}{*}{$\begin{array}{l}\text { Obsessive- } \\
\text { compulsive }\end{array}$} & $r$ & -0.025 & $0.134^{\star \star \star}$ & 0.028 \\
\hline & $p$-value & 0.463 & $<0.001$ & 0.413 \\
\hline \multirow[t]{2}{*}{ Paranoid ideation } & $r$ & -0.008 & $0.202^{\star \star \star}$ & $0.077^{\star}$ \\
\hline & $p$-value & 0.820 & $<0.001$ & 0.024 \\
\hline \multirow[t]{2}{*}{ Psychoticism } & $r$ & $-0.137^{\star \star \star}$ & $0.201^{\star \star \star}$ & $0.097^{\star *}$ \\
\hline & $p$-value & $<0.001$ & $<0.001$ & 0.004 \\
\hline \multirow[t]{2}{*}{ Somatization } & $r$ & -0.024 & $0.13^{\star \star \star}$ & 0.022 \\
\hline & $p$-value & 0.487 & $<0.001$ & 0.525 \\
\hline \multirow{3}{*}{$\begin{array}{l}\text { Overall BSI-53 } \\
\text { score }\end{array}$} & $r$ & -0.019 & $0.157^{\star \star \star}$ & 0.034 \\
\hline & & & & \\
\hline & $p$-value & 0.588 & $<0.001$ & 0.317 \\
\hline
\end{tabular}

The BSI-53 subscales measure the prevalence of symptoms, but do not constitute a clinical diagnosis. Pearson's $r$ coefficient was used to correlate the variables. ${ }^{*} p<0.05,{ }^{* *} p<0.01,{ }^{* * *} p<0.001$.

\section{DISCUSSION}

Our study concluded that individuals who live with older adults (age $>60$ ) had significantly lower Immunity Perception scores than subjects that do not. Complementarily, respondents who live with children $($ age $<12)$ tend to endorse the Immunity Perception and the belief that COVID-19 situation is being exaggerated; such beliefs may detonate risky health behaviors in such populations. Results showed that increases in Coronavirus Concern scores are associated with increases in age and viceversa. This could be related to the fact that older age is considered a risk factor for ARDS and death (Rothan and Byrareddy, 2020). On the other side, younger age has been related to mild disease and better health outcomes (Verity et al., 2020). That is not to say that young people are immune to the virus, therefore, adolescents and young people should receive information about COVID19. This can be achieved through digital platforms that promote age-friendly content (United Nations Population Fund, 2020).

The most intense symptoms reported by respondents were related to the obsessive-compulsive domain, followed by anxiety and interpersonal sensitivity. These findings are consistent with other studies that reported that individuals exposed to information related to outbreaks experienced higher anxiety symptoms related to health and obsessive-compulsive behavior (Brand et al., 2013). Congruently, our study found a significant positive, although weak, correlation between Coronavirus Concern, anxiety and social phobia. Given the epidemiologic nature of COVID-19, prevention strategies are partly based on social distancing, implying that people should be at least a meter apart from each other (World Health Organization, 2020a). In this sense, many countries around the world recommend their citizens to avoid public spaces (Public Health Ontario, 2020), therefore an increase in social phobia indicators is a natural response to such circumstances.

Another of our findings determined a small negative relationship between the presence of depression symptoms and Coronavirus Awareness. To understand this, the reader must consider that apathy is a common characteristic of depressive disorders (American Psychiatric Association, 2013). In certain populations, respondents with higher depression scores may be less concerned about health issues, indicating a higher level of self-neglect (Hansen et al., 2017). However, these results should be considered with caution as the BSI-53 only screens for symptoms of depression and does not constitute a clinical diagnosis.

Hostility and interpersonal sensitivity symptoms are positively related to the belief that the COVID-19 impact and responses are being exaggerated. Previous research suggests that these traits are highly associated with passive coping strategies (Mao et al., 2003), however, more research is still needed to clearly understand this dynamic. Another symptom of interest corresponds to the paranoid ideation domain, which correlates positively with both the Exaggerated Perception and the Immunity Perception subscales. Respondents with higher paranoid ideation and psychoticism could distrust public media and the government position regarding the impact of COVID19 in society, minimizing its repercussions. In this sense, prior

TABLE 6 | Direct effects of CAS-10 subscales over ATSPPH-SF subscales.

\begin{tabular}{|c|c|c|c|c|c|c|c|}
\hline Predictor & Outcome & Estimate & Std. error & z-value & $p$ & Lower 95\% Cl & Upper $95 \%$ Cl \\
\hline Coronavirus concern & Openness to seeking treatment & 0.178 & 0.060 & 2.974 & 0.003 & 0.039 & 0.315 \\
\hline Exaggerated perception & & -0.008 & 0.036 & -0.224 & 0.823 & -0.078 & 0.068 \\
\hline Immunity perception & & -0.062 & 0.036 & -1.744 & 0.081 & -0.140 & 0.012 \\
\hline Coronavirus concern & Value and need in seeking treatment & 0.033 & 0.059 & 0.569 & 0.569 & -0.097 & 0.159 \\
\hline Exaggerated perception & & -0.124 & 0.036 & -3.451 & $<0.001$ & -0.205 & -0.053 \\
\hline Immunity perception & & -0.104 & 0.035 & -2.964 & 0.003 & -0.181 & -0.029 \\
\hline
\end{tabular}

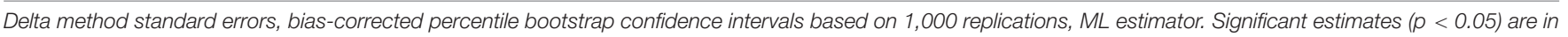
boldface. 
TABLE 7 | Indirect effects of CAS-10 subscales on ATSPPH-SF subscales.

\begin{tabular}{|c|c|c|c|c|c|c|c|c|}
\hline Predictors & Mediators & Outcomes & Estimate & Std. error & $z$-value & $p$ & Lower $95 \% \mathrm{Cl}$ & Upper $95 \%$ Cl \\
\hline \multirow[t]{11}{*}{ Coronavirus concern } & Anxiety & $\begin{array}{l}\text { Openness to seeking } \\
\text { treatment }\end{array}$ & 0.060 & 0.022 & 2.737 & 0.006 & 0.022 & 0.116 \\
\hline & Depression & & 0.002 & 0.005 & 0.451 & 0.652 & -0.005 & 0.032 \\
\hline & Hostility & & -0.004 & 0.005 & -0.694 & 0.488 & -0.028 & 0.004 \\
\hline & Interpersonal sensitivity & & 0.001 & 0.003 & 0.375 & 0.707 & -0.005 & 0.021 \\
\hline & Obsessive-compulsive & & 0.005 & 0.009 & 0.576 & 0.564 & -0.008 & 0.037 \\
\hline & Somatization & & -0.003 & 0.006 & -0.535 & 0.593 & -0.026 & 0.008 \\
\hline & Anxiety & $\begin{array}{l}\text { Value and need in seeking } \\
\text { treatment }\end{array}$ & 0.036 & 0.013 & 2.677 & 0.007 & 0.012 & 0.072 \\
\hline & Depression & & -0.006 & 0.012 & -0.492 & 0.623 & -0.036 & 0.018 \\
\hline & Phobic anxiety & & -0.008 & 0.006 & -1.437 & 0.151 & -0.028 & 0.001 \\
\hline & Hostility & & -0.014 & 0.011 & -1.299 & 0.194 & -0.04 & 0.007 \\
\hline & Somatization & & -0.015 & 0.009 & -1.659 & 0.097 & -0.038 & -0.001 \\
\hline \multirow[t]{11}{*}{$\begin{array}{l}\text { Exaggerated } \\
\text { perception }\end{array}$} & Anxiety & $\begin{array}{l}\text { Openness to seeking } \\
\text { treatment }\end{array}$ & -0.012 & 0.01 & -1.244 & 0.214 & -0.042 & 0.005 \\
\hline & Depression & & 0.002 & 0.004 & 0.459 & 0.646 & -0.005 & 0.021 \\
\hline & Phobic anxiety & & 0.005 & 0.004 & 1.108 & 0.268 & -0.001 & 0.022 \\
\hline & Hostility & & 0.002 & 0.003 & 0.545 & 0.586 & -0.004 & 0.017 \\
\hline & Interpersonal sensitivity & & 0.001 & 0.002 & 0.253 & 0.801 & -0.005 & 0.009 \\
\hline & Obsessive-compulsive & & -0.004 & 0.006 & -0.742 & 0.458 & -0.023 & 0.006 \\
\hline & Paranoid ideation & & -0.001 & 0.005 & -0.098 & 0.922 & -0.014 & 0.010 \\
\hline & Psychoticism & & 0.001 & 0.003 & 0.044 & 0.965 & -0.007 & 0.012 \\
\hline & Somatization & & 0.004 & 0.004 & 0.849 & 0.396 & -0.003 & 0.018 \\
\hline & Anxiety & $\begin{array}{l}\text { Value and need in seeking } \\
\text { treatment }\end{array}$ & 0.026 & 0.017 & 1.534 & 0.125 & -0.002 & 0.071 \\
\hline & Somatization & & -0.001 & 0.002 & -0.198 & 0.843 & -0.014 & 0.006 \\
\hline \multirow[t]{18}{*}{ Immunity perception } & Anxiety & $\begin{array}{l}\text { Openness to seeking } \\
\text { treatment }\end{array}$ & 0.016 & 0.01 & 1.523 & 0.128 & -0.002 & 0.044 \\
\hline & Depression & & 0.006 & 0.012 & 0.529 & 0.597 & -0.019 & 0.039 \\
\hline & Phobic anxiety & & -0.002 & 0.005 & -0.42 & 0.674 & -0.015 & 0.009 \\
\hline & Hostility & & 0.002 & 0.010 & 0.243 & 0.808 & -0.017 & 0.025 \\
\hline & Interpersonal sensitivity & & -0.015 & 0.009 & -1.724 & 0.085 & -0.043 & -0.001 \\
\hline & Obsessive-compulsive & & -0.001 & 0.010 & -0.027 & 0.978 & -0.024 & 0.023 \\
\hline & Paranoid ideation & & -0.040 & 0.014 & -2.827 & 0.005 & -0.072 & -0.013 \\
\hline & Psychoticism & & 0.005 & 0.012 & 0.459 & 0.646 & -0.015 & 0.032 \\
\hline & Somatization & & -0.002 & 0.008 & -0.211 & 0.833 & -0.018 & 0.016 \\
\hline & Anxiety & $\begin{array}{l}\text { Value and need in seeking } \\
\text { treatment }\end{array}$ & -0.005 & 0.005 & -1.032 & 0.302 & -0.028 & 0.002 \\
\hline & Depression & & -0.002 & 0.004 & -0.489 & 0.625 & -0.018 & 0.005 \\
\hline & Phobic anxiety & & 0.001 & 0.003 & 0.408 & 0.683 & -0.005 & 0.011 \\
\hline & Hostility & & -0.001 & 0.001 & -0.226 & 0.821 & -0.009 & 0.004 \\
\hline & Interpersonal sensitivity & & 0.001 & 0.005 & 0.266 & 0.791 & -0.009 & 0.015 \\
\hline & Obsessive-compulsive & & 0.001 & 0.002 & 0.027 & 0.978 & -0.007 & 0.010 \\
\hline & Paranoid ideation & & -0.001 & 0.007 & -0.098 & 0.922 & -0.018 & 0.013 \\
\hline & Psychoticism & & 0.001 & 0.001 & 0.043 & 0.965 & -0.006 & 0.010 \\
\hline & Somatization & & 0.001 & 0.002 & 0.206 & 0.837 & -0.005 & 0.010 \\
\hline
\end{tabular}

The BSI-53 subscales measure the prevalence of symptoms, but do not constitute a clinical diagnosis. Delta method standard errors, bias-corrected percentile bootstrap confidence intervals based on 1,000 replications, ML estimator. Significant estimates $(p<0.05)$ are in boldface. 
TABLE 8 | Total indirect effects of CAS-10 subscales on ATSPPH-SF subscales.

\begin{tabular}{|c|c|c|c|c|c|c|c|}
\hline Predictor & Outcome & Estimate & Std. Error & z-value & $p$ & Lower $95 \% \mathrm{Cl}$ & Upper $95 \% \mathrm{Cl}$ \\
\hline \multirow[t]{2}{*}{ Coronavirus concern } & Openness to seeking treatment & 0.015 & 0.022 & 0.693 & 0.488 & -0.03 & 0.06 \\
\hline & Value and need in seeking treatment & -0.009 & 0.010 & -0.831 & 0.406 & -0.035 & 0.013 \\
\hline \multirow[t]{2}{*}{ Exaggerated perception } & Openness to seeking treatment & -0.004 & 0.008 & -0.582 & 0.561 & -0.023 & 0.015 \\
\hline & Value and need in seeking treatment & -0.004 & 0.022 & -0.184 & 0.854 & -0.056 & 0.040 \\
\hline \multirow[t]{2}{*}{ Immunity perception } & Openness to seeking treatment & -0.029 & 0.010 & -2.813 & 0.005 & -0.054 & -0.008 \\
\hline & Value and need in seeking treatment & -0.005 & 0.008 & -0.66 & 0.509 & -0.024 & 0.012 \\
\hline
\end{tabular}

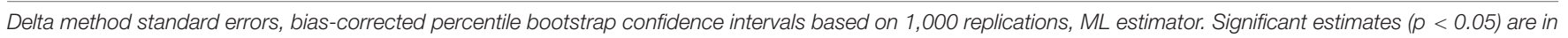
boldface.

TABLE 9 | Total effects of CAS-10 subscales on ATSPPH-SF subscales.

\begin{tabular}{|c|c|c|c|c|c|c|c|}
\hline Predictor & Outcome & Estimate & Std. Error & $z$-value & $p$ & Lower $95 \%$ Cl & Upper $95 \%$ Cl \\
\hline Coronavirus concern & Openness to seeking treatment & 0.193 & 0.057 & 3.366 & $<0.001$ & 0.054 & 0.325 \\
\hline Exaggerated perception & & -0.017 & 0.036 & -0.463 & 0.643 & -0.093 & 0.054 \\
\hline Immunity perception & & -0.067 & 0.036 & -1.849 & 0.064 & -0.145 & 0.009 \\
\hline Coronavirus concern & Value and need in seeking treatment & 0.029 & 0.056 & 0.519 & 0.604 & -0.108 & 0.151 \\
\hline Exaggerated perception & & -0.153 & 0.036 & -4.292 & $<0.001$ & -0.231 & -0.079 \\
\hline Immunity perception & & -0.109 & 0.036 & -3.072 & 0.002 & -0.185 & -0.032 \\
\hline
\end{tabular}

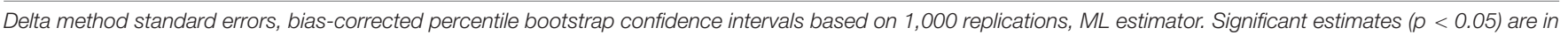
boldface.

research has determined a link between paranoid ideation, distrust (Kirk et al., 2013), and the endorsing of conspiracy theories (Darwin et al., 2011).

A similar trend has been suggested for psychoticism and its relationship to medical mistrust and conspiracy theories during pandemic outbreaks (Moukaddam and Shah, 2020), this could help understand the positive relationship between COVID19 Exaggerated Perception subscale and psychotic symptoms. Although there is a clear relationship between stress exposure and psychotic symptoms (Van Winkel et al., 2008), our research found a negative and weak relationship between Coronavirus Concern and psychoticism. This lack of concern may be explained by the positive correlation of psychoticism with Exaggerated Perception and Immunity Perception. Therefore, respondents who score higher on psychotic symptoms are also less preoccupied with the COVID-19 situation and are more likely to believe that the media exaggerates this situation and that they are not likely to get infected with COVID-19.

This study revealed that most individuals are constantly informing themselves about the COVID-19 current situation and they believe it is a serious problem. However, there is a significant number of respondents that believe the media is exaggerating the situation. Such set of beliefs clearly poses contagion risks that should be addressed by local governments. This could be achieved by promoting health literacy and epidemic prevention strategies (Wang and Wang, 2020), by constantly informing the public about the prevalence and incidence of COVID-19 cases and implementing campaigns designed to educate citizens regarding self-protection measures (Hu et al., 2020).

A relevant finding was that Coronavirus Concern had a positive and direct effect on OSPT, this relationship was significantly mediated by anxiety scores. This is consistent with a study that reported that people who experience anxiety symptoms have, more often, a better attitude toward seeking psychological help (Roness et al., 2005). This could be related to the fact that anxiety symptoms can quickly progress and become harder to manage by oneself in comparison to other disorders. Immunity Perception had a negative effect on OSPT. In this sense, previous research has found that the presence of subjective needs is positively related to attitudes toward seeking psychological help (Nagai, 2015). Translated to our study, this can signify that respondents with high Immunity Perception scores do not feel the need to seek psychological attention. However, given the small determinant coefficients of the results, other variables besides the presence of psychological symptoms should be considered to understand people's attitudes toward seeking professional psychological help (Nunes Baptista and Zanon, 2017).

Health care systems should take into consideration that the COVID-19 crisis may exacerbate symptoms related to anxiety, depression, and obsessive-compulsive behavior. A way to mitigate this situation could be to provide professional psychological help through the use of online resources, such as they did in China in different stages of the pandemic. In this sense, two simultaneous activities during crisis intervention may be considered: (1) mitigate the fear of the disease and, (2) help coping with difficulties in the adaptation process (Zhang et al., 2020). Since the current pandemic is affecting mental health, the Honduran health care system should take technology as an advantage to reach patients that are experiencing these negative symptoms. Given our results, such response system should focus on interventions designed to mitigate anxiety symptoms. In this sense, recent studies have found that the use of mobile-phone applications based on coachsupported platforms are effective in treating symptoms of anxiety (Graham et al., 2020). 
The current research did not took into consideration the potential effects of social distancing and quarantine measures that may impact mental health; more research is yet needed in this subject. Future studies should also focus on specific groups that, given the nature of their work, are in constant risk of infection. Frontline workers (like health care professionals and police force members) have more probabilities of experiencing stressors related to stigmatization, biosecurity procedures, an increased workload and the fear of transmitting COVID-19 to others. Additional variables such as lifestyle and physical activity should also be considered in future studies (Zhou et al., 2020). A mixedmethods approach may provide a more profound comprehension of this phenomenon.

The cross-sectional nature of the current study, which focused on the initial stages of the COVID-19 pandemic, only gives a limited glimpse of the relationship between pandemic outbreaks and mental health indicators of the affected populations. More longitudinal data is still needed on the subject to better determine the causal relationships between variables. Data collection for this research was made between the 16th and the 23rd of March, during this time Honduras reported 30 confirmed COVID19 cases with 0 fatalities. However, as of May 27th, 2020, the country reported 4,401 confirmed cases and 188 deaths (Honduras Health Secretary, 2020), this increase in COVID19 cases, in addition to the effects of social confinement and the restriction of liberties, are not accounted for in our research. Another limitation of our study is the non-probabilistic sampling method that was used, which may restrict the inferential capability of our results. Future studies should also explore alternative data analysis, such as non-parametric and Bayesian approaches to further corroborate the results presented in the current research.

The proposed mediation model stated an unidirectional influence of Coronavirus Awareness, mental health indicators and attitudes toward seeking psychological help. However, this relationship could be bidirectional. In this sense, COVID-19 awareness may influence the prevalence of psychopathological indicators. But, such indicators may also have an impact on Coronavirus Awareness itself (as was discussed regarding depression and paranoid ideation symptoms). Further studies

\section{REFERENCES}

American Psychiatric Association (2013). Diagnostic and Statistical Manual of Mental Disorders, 5th Edn, Arlington: American Psychiatric Publishing.

Biesanz, J., Falk, C., and Savalei, V. (2010). Assessing mediational models: testing and interval estimation for indirect effects. Multivar. Behav. Res. 45, 661-701. doi: 10.1080/00273171.2010.498292

Blakey, S. M., and Abramowitz, J. S. (2017). Psychological predictors of health anxiety in response to the Zika Virus. J. Med. Psychol. Med. Settings 24, 270-278. doi: 10.1007/s10880-017-9514-y

Brand, J., McKay, D., Wheaton, D., and Abramowitz, J. S. (2013). The relationship between obsessive compulsive beliefs and symptoms, anxiety and disgust sensitivity, and swine flu fears. J. Obses. Compuls. Relat. Disord. 2, 200-206. doi: 10.1016/j.jocrd.2013.01.007

BrckaLorenz, A., Chiang, Y., and Nelson-Laird, T. (2013). Internal Consistency. FSSE Psychometric Portfolio. Available online at: http://fsse.indiana.edu/pdf/pp/ 2017/FSSE17_Internal_Consistency_Reliability.pdf (accessed March 29, 2020). are still needed to clarify this dynamic. On the other hand, the BSI-53 measures the prevalence and intensity of different psychological symptoms, but it does not constitute a clinical diagnosis. Finally, given that the current research had a limited psychopathological-based approach to mental health, future studies should include positive and protective variables like resilience, subjective well-being, among other factors that respond to a more holistic, humanistic, and positive concept of mental health.

\section{DATA AVAILABILITY STATEMENT}

The raw data supporting the conclusions of this article will be made available by the authors, without undue reservation.

\section{ETHICS STATEMENT}

Ethical review and approval was not required for the study on human participants in accordance with the local legislation and institutional requirements. Written informed consent for participation was not required for this study in accordance with the national legislation and the institutional requirements.

\section{AUTHOR CONTRIBUTIONS}

ML-B and AL-B were responsible for the questionnaire design, data collection, and statistical analysis. CM-M and CM-S were responsible for building the theoretical and contextual framework of the study, as well as data interpretation. All authors contributed to the article and approved the submitted version.

\section{ACKNOWLEDGMENTS}

We would like to thank Yaraní Echenique for her help in the data collection process and Cindy Santos-Midence and Gabriela Vásquez for assisting in the language adaptation process.

Brooks, S. K., Webster, R., Smith, L. E., Woodland, L., Wessely, S., Greenberg, N., et al. (2020). The psychological impact of quarantine and how to reduce it: rapid review of the evidence. Lancet 395, 912-920. doi: 10.1016/S0140-6736(20) 30460-8

Caicedo-Ochoa, Y., Rebellón-Sánchez, D., Peñaloza-Rallón, M., Cortés-Motta, H. F., and Méndez-Fandiño, Y. R. (2020). Effective reproductive number estimation for initial stage of COVID-19 pandemic in Latin American countries. Intern. J. Infect. Dis. 95, 316-318. doi: 10.1016/j.ijid.2020.04.069

Caplan, S. (2019). Intersection of cultural and religious beliefs about mental health: latinos in the faith-based setting. Hispan. Health Care Intern. 17, 4-10. doi: $10.1177 / 1540415319828265$

Cohen, J. A. (1992). Power primer. Psychol. Bull. 112, 155-159. doi: 10.1037//00332909.112.1.155

Colizzi, M., Bortoletto, R., Silvestri, M., Mondini, F., Puttini, E., Cainelli, C., et al. (2020). Medically unexplained symptoms in the times of COVID-19 pandemic: a case-report. Brain Behav. Immun. Health 5:100073. doi: 10.1016/j.bbih.2020. 100073 
Coolican, H. (2004). Research Methods and Statistics in Psychology. London: Routledge.

Darwin, H., Neave, N., and Holmes, J. (2011). Belief in conspiracy theories. The role of paranormal belief, paranoid ideation and schizotypy. Pers. Individ. Differ. 50, 1289-1293. doi: 10.1016/j.paid.2011.02.027

Debanjan, B. (2020). The other side of COVID-19: impact on obsessive compulsive disorder (OCD) and hoarding. Psychiatry Res. 288:112966. doi: 10.1016/j. psychres.2020.112966

Derogatis, L. R. (1993). Brief Symptom Inventory (BSI), Administration, Scoring, and Procedures Manual, 3rd Edn, Minneapolis: MN: NCS Pearson.

Dervrim, I., and Bayram, N. (2020). Infection control practices in children during COVID-19 pandemic: differences from adults. Am. J. Infect. Control 48, 933939. doi: $10.1016 /$ j.ajic.2020.05.022

El Hayek, S., Ali Cheaito, M., Nofal, M., Abdelrahman, D., Adra, A., Al Shamli, S., et al. (2020). Geriatric mental health and COVID-19: an eye-opener to the situation of the Arab countries in the Middle East and North Africa Region. Am. J. Geriatr. Psychiatry 28, 1058-1069. doi: 10.1016/j.jagp.2020.05.009

Fernández Poncela, A. (2012). Psicología de masas, identidad social, epidemias y rumores: la influenza en México. Sociológica 27, 189-230.

Ferrando, S. J., Klepacz, L., Lynch, S., Tavakkoli, M., Dornbush, R., Baharani, R., et al. (2020). COVID-19 Psychosis: a potential new neuropsychiatric condition triggered by novel coronavirus infection and the inflammatory response? Psychosomatics 61, 551-555. doi: 10.1016/j.psym.2020.05.012

Field, A. (2009). Discovering Statistics Using SPSS. Thousand Oaks, CA: SAGE Publication.

Fischer, E., and Farina, A. (1995). Attitudes toward seeking professional psychological help: a shortened form and considerations for research. J. College Stud. Dev. 36, 368-373.

Frederiksen, B., Gomez, I., Salganicoff, A., and Ranji, U. (2020). Coronavirus: A Look at Gender Differences in Awareness and Actions. Available online at: https://www.kff.org/coronavirus-covid-19/issue-brief/coronavirus-a-lookat-gender-differences-in-awareness-and-actions/ (accessed June 11, 2020).

Graham, A., Greene, C., Kwasny, M., Kaiser, S., Lieponis, P., Powell, T., et al. (2020). Coached mobile App platform for the treatment of depression and anxiety among primary care patients: a randomized clinical trial. JAMA Psychiatry 77, 906-914. doi: 10.1001/jamapsychiatry.2020.1011

Hamel, L., Lopes, L., Muñana, C., Kates, J., Michaud, J., and Brodie, M. (2020). Kaiser Family Foundation. Available online at: https://www.kff.org/ global-health-policy/poll-finding/kff-coronavirus-poll-march-2020/ (accessed June 11, 2020).

Hansen, M., Flores, D., Coverdale, J., and Burnett, J. (2017). Correlates of depression in self-neglecting older adults: a cross-sectional study examining the role of alcohol abuse and pain in increasing vulnerability. J. Elder Abuse Negl. 28, 41-56. doi: 10.1080/08946566.2015.1136252

Honduras Health Secretary (2020). Coronavirus COVID-19 en Honduras [Coronavirus COVID-19 in Honduras]. Available online at: https: //covid19honduras.org/ (accessed May 27, 2020).

Hu, D., Lou, X., Xu, Z., Meng, N., Xie, Q., Zhang, M., et al. (2020). More effective strategies are required to strengthen public awareness of COVID-19: evidence from google trends. J. Glob. Health 10:011003.

Huremovié, D. (ed.) (2019). Psychiatry of Pandemics. A Mental Health Response to Infection Outbreak. Berlin: Springer.

Inter-Agency Standing Committee (2020). Interim Briefing Note. Adressing Mental Health and Psychosocial Aspects of COVID-19 Outbreak. Version 1.5. Available online at: https://interagencystandingcommittee.org/iasc-referencegroup-mental-health-and-psychosocial-support-emergency-settings/interimbriefing (accessed March 30, 2020).

Kirk, H., Gilmour, A., Dudley, R., and Riby, D. (2013). Paranoid ideation and assessments of trust. J. Exper. Psychopathol. 4, 360-367. doi: 10.5127/jep.02 7812

Korkeila, J., Lehtinen, V., Bijl, R., Dalgard, O., Kovess, V., Morgan, A., et al. (2003). Establishing a set of mental health indicators for Europe. Scand. J. Public Health 31, 451-549. doi: 10.1080/14034940210165208

Kwasi Ahorsu, D., Lin, C., Imani, V., Saffari, M., Griffiths, M., and Pakpour, A. (2020). The Fear of COVID-19 scale: development and initial validation. Intern. J. Ment. Health Addict. doi: 10.1007/s11469-020-00270-8

Li, M., Wang, M., Shou, Y., Zhong, C., Ren, F., Zhang, X., et al. (2018). Psychometric properties and measurement invariance of the brief symptom inventory-18 among chinese insurance employees. Front. Psychol. 9:519. doi: 10.3389/fpsyg.2018.00519

Liu, S., Zhang, C., Xiang, Y., Liu, Z., Hu, S., and Zhang, B. (2020). Online mental health services in China during the COVID-19 outbreak. Lancet Psychiatry 7, 17-18. doi: 10.1016/S2215-0366(20)30077-8

Mao, W., Bardwell, W., Major, J., and Dimsdale, J. (2003). Coping strategies, hostility, and depressive symptoms: a path model. Intern. J. Behav. Med. 10, 331-342. doi: 10.1207/s15327558ijbm1004_4

Mascayano, F., Lips Castro, W., Mena Poblete, C., and Manchego Soza, C. (2015). Estigma hacia los trastornos mentales: características e intervenciones. Salud Ment. 38, 53-58.

Masillo, A., Valmaggia, L., Saba, R., Brandizzi, M., Lindau, J., Solfanelli, A., et al. (2015). Interpersonal sensitivity and functioning impairment in youth at ultrahigh risk for psychosis. Eur. Child Adolesc. Psychiatry 25, 7-16. doi: 10.1007/ s00787-015-0692-6

Mesa Vieira, C., Franco, O. H., Gómez Restrepo, C., and Abel, T. (2020). COVID19: the forgotten priorities of the pandemic. Maturitas 136, 38-41. doi: 10.1016/ j.maturitas.2020.04.004

Mohammad, A., Zerbetto, R., Simona, R. T., Bisharat, B., Mahamid, M., Amital, H., et al. (2019). Psychometric properties of the brief symptom inventory in nomophobic subjects: insights from preliminary confirmatory factor, exploratory factor, and clustering analyses in a sample of healthy Italian volunteers. Psychol. Res. Behav. Manag. 12, 145-154. doi: 10.2147/PRBM. S173282

Morrow-Howell, N., Galucia, N., and Swinford, E. (2020). Recovering from the COVID-19 pandemic: a focus on older adults. J. Aging Soc. Policy 32, 526-535. doi: $10.1080 / 08959420.2020 .1759758$

Moukaddam, N., and Shah, A. (2020). Psychiatrists Beware! The Impact of COVID19 and Pandemics on Mental Health: Page 2 of 2. Cranbury, NJ: Psychiatric Times.

Mushtaq, A., Fatima, B., Fatema, B., Syed, H., and Sohali, H. (2017). Interpersonal sensitivity in the at-risk mental state for psychosis in Karachi, Pakistan. Eur. Psychiatry 41:S563. doi: 10.1016/j.eurpsy.2017.01.819

Nagai, S. (2015). Predictors of help-seeking behavior: distinction between helpseeking intentions and help-seeking behavior. Jpn. Psychol. Res. 57, 313-322. doi: 10.1111/jpr.12091

Nunes Baptista, M., and Zanon, C. (2017). Why not seek therapy? the role of stigma and psychological symptoms in college students. Paidéia 27, 76-83. doi: 10.1590/1982-43272767201709

Public Health Ontario (2020). Coronavirus Disease 2019 (COVID-19), How to Self-Monitor. Available online at: https://www.publichealthontario.ca/-/ media/documents/ncov/factsheet-covid-19-self-monitor.pdf (accessed March 28, 2020).

Rajkumar, R. P. (2020). COVID-19 and mental health: a review of the existing literature. Asian J. Psychiatry 52:102066. doi: 10.1016/j.ajp.2020.10 2066

Rodríguez-Morales, A. J., Gallego, V., Escalera-Antenaza, J. P., Méndez, C. A., Zambrano, L. I., Franco-Paredes, C., et al. (2020). COVID-19 in Latin America: the implications of the first confirmed case in Brazil. Travel Med. Infect. Dis. 35. doi: 10.1016/j.tmaid.2020.101613

Roness, A., Mykletun, A., and Dahl, A. A. (2005). Help-seeking behaviour in patients with anxiety disorder and depression. Acta Psychiatr. Scand. 111, 51-58. doi: 10.1111/j.1600-0447.2004.00433.x

Rothan, H. A., and Byrareddy, S. N. (2020). The epidemiology and pathogenesis of Coronavirus disease (COVID-19) outbreak. J. Autoimmun. 109:102433. doi: 10.1016/j.jaut.2020.102433

Roy, D., Tripathy, S., Kumar, K., Sharma, N., Verma, S. K., and Kaushal, V. (2020). Study of knowledge, attitude, anxiety \& perceived mental healthcare need in Indian population during COVID-19 pandemic. Asian J. Psychiatry 51:102083. doi: $10.1016 /$ j.ajp.2020.102083

Rubin, G. J., Potts, H. W. W., and Michie, S. (2010). The impact of communications about swine flu (influenza A1H1v) on public responses to the outbreak: results from 36 national telephone surveys in the UK. Health Technol. Assess. 14, 183-266. doi: 10.3310/hta14340-03

Rubin, G. J., and Wessly, S. (2020). The psychological effects of quarantining a city. BMJ 368:m313. doi: 10.1136/bmj.m313

Ruckenstein, M. J., and Staab, J. P. (2001). The basic symptom inventory53 and its use in the management of patients with psychogenic 
dizziness. Otolaryngol. Head Neck Surg. 125, 533-536. doi: 10.1067/mhn.2 001.119515

School of Psychological Sciences (2020). La UNAH te Escucha [The UNAH is Listening]. Statistical Report. Tegucigalpa: UNAH.

Shereen, M. A., Khan, S., Kazmi, A., Bashir, N., and Siddique, R. (2020). COVID19 infection: origin, transmission, and characteristics of human coronaviruses. J. Adv. Res. 24, 91-98. doi: 10.1016/j.jare.2020.03.005

Sim, K., Huak Chan, Y., Chong, P. N., Chua, H. C., and Wen Soon, S. (2010). Psychosocial and coping responses within the community health care setting towars a national outbreak of an infectious disease. J. Psychosom. Res. 68, 195-202. doi: 10.1016/j.jpsychores.2009.04.004

The Jamovi Project (2019). Jamovi 1.1. Available online at: https://www.jamovi.org/ (accessed March 28, 2020).

Torres, L., Magnus, B., and Najar, N. (2020). Assessing the psychometric proprieties of the attitudes toward seeking professional psychological help scale-short form (ATSPPH-SF) among latino adults. Assessment 8, 211-224. doi: 10.1177/ 1073191119899470

United Nations Population Fund (2020). Coronavirus Disease (COVID-19) Preparedness and Response UNFPA Interim Technical Brief. Technical Brief. Available online at: https://www.unfpa.org/resources/adolescents-and-youngpeople-coronavirus-disease-covid-19 (accessed March 26, 2020).

Van Bortel, T., Basnayake, A., Wurie, F., Jambai, M., Koroma, A. S., Muana, A. T., et al. (2016). Psychosocial effects of an Ebola outbreak at individual, community and international levels. Bull. World Health Organ. 94, 210-214.

Van Winkel, R., Stefanis, N., and Myin-Germeys, I. (2008). Psychosocial stress and psychosis. a review of the neurobiological mechanisms and the evidence for gene-stress interaction. Schizophren. Bull. 34, 1095-1105. doi: 10.1093/schbul/ sbn 101

Verity, R., Okell, L., Dorigatti, L., Winskill, P., Whittaker, C., Imai, N., et al. (2020). Estimates of the severity of coronavirus disease 2019: a model-based analysis. Lancet Infect. Dis. 20, 1-9. doi: 10.1016/S1473-3099(20)30243-7

Vinkers, C., van Amelsvoort, T., Bisson, J., Branchi, I., Cryan, J., Domschke, K., et al. (2020). Stress resilience during the coronavirus pandemic. Eur. Neuropsychopharmacol. 35, 12-16. doi: 10.1016/j.euroneuro.2020.05.003

Wang, C., Pan, R., Wan, X., Tan, Y., Xu, L., Ho, C., et al. (2020). Immediate psychological responses and associated factors during the initial stage of the 2019 Coronavirus Disease (COVID-19) epidemic among the general population in China. Intern. J. Environ. Res. Public Health 17:1729. doi: 10.3390/ ijerph17051729

Wang, J., and Wang, Z. (2020). Strengths, weaknesses, opportunities and threats (SWOT) analysis of China's prevention and control. Intern. J. Environ. Res. Public Health 17:2235. doi: 10.3390/ijerph17072235

Wilder-Smith, A., Chiew, C. J., and Lee, V. J. (2020). Can we contain the COVID19 outbreak with the same measures as for SARS?. Lancet Infect. Dis. 20, 1-6. doi: 10.1016/S1473-3099(20)30129-8

World Health Organization (2003). Investing in Mental Health. Geneva: WHO.

World Health Organization (2020a). Mental Health and Psychosocial Considerations During the COVID-19 Outbreak. Geneva: WHO.

World Health Organization (2020b). Coronavirus Disease 2019 (COVID-19) Situation Report - 73. Geneva: WHO.

Wu, C., Chen, X., Cai, Y., Xia, J., Zhou, X., Xu, S., et al. (2020). Risk factors associated with acute respiratory distress syndrome and death in patients with Coronavirus disease 2019 pneumonia in Wuhan, China. JAMA Intern. Med. 180, 934-943. doi: 10.1001/jamainternmed.2020.0994

Zhang, J., Wu, W., Zhao, X., and Zhang, W. (2020). Recommended psychological crisis intervention response to the 2019 novel coronavirus pneumonia outbreak in China: a model of West China Hospital. Precis. Clin. Med. 3, 3-8. doi: 10.1093/pcmedi/pbaa006

Zhou, Y., Wang, W., Sun, Y., Qian, W., Liu, Z., Wang, R., et al. (2020). The prevalence and risk factors of psychological disturbances of frontline medical staff in china under the COVID-19 epidemic: workload should be concerned. J. Affect. Disord. 277, 510-514. doi: 10.1016/j.jad.2020.08.059

Conflict of Interest: The authors declare that the research was conducted in the absence of any commercial or financial relationships that could be construed as a potential conflict of interest.

Copyright (C) 2021 Landa-Blanco, Landa-Blanco, Mejía-Suazo and MartínezMartinez. This is an open-access article distributed under the terms of the Creative Commons Attribution License (CC BY). The use, distribution or reproduction in other forums is permitted, provided the original author(s) and the copyright owner(s) are credited and that the original publication in this journal is cited, in accordance with accepted academic practice. No use, distribution or reproduction is permitted which does not comply with these terms. 